\title{
Tourism 'Vs.' Ecotourism - People Perception in Upper Nilgiris, Tamil Nadu, India
}

\author{
Veeramani $\mathrm{A}^{1}$, Mohanakrishnan $\mathrm{H}^{2}$, Ramakrishnan $\mathrm{B}^{2}$, Nithya $\mathrm{J}^{2}$, \\ Samson $\mathrm{A}^{2}$ and Karthick $\mathrm{S}^{2}$ \\ ${ }^{1}$ Department of Zoology, Government Arts College (Autonomous), India \\ ${ }^{2}$ Department of Zoology and Wildlife Biology, Government Arts College, India
}

*Corresponding author: Veeramani A, Assistant Professor, Department of Zoology, Government Arts College (Autonomous), Kumbakonam - 612 002, India, Tel: +91-8124881520; Email: wildveera@gmail.com

\section{Abstract}

Tourism is an important contributor to enrich the economic background of many countries. Tourism is a composition of activities, services and industries that deliver a travel experience, transportation, accommodation, eating and drinking, establishments, shops, entertainment, activity facilities and other hospitality services available for individuals or groups travelling away from home. Udhagamandalam alice Ooty is one of the mass tourism destination located in the district called Nilgiris, A Blue Mountains of the Western Ghats; it draws a large number of tourists every year. The study was indented to bring out the interest and preferences of tourists visiting Ooty, to examine the satisfaction of tourists with respect to visiting Ooty, to investigate the problems encountered by the tourists while visiting the hill station and to identify the factors influencing the tourists to visit again to this hill stations. The study was conducted where the places of interest of tourists inside Ooty municipal limit are: 1. Botanical Garden, 2. Boat House and 3. Rose Garden. Questionnaire was surveyed with the tourists of Tamil Nadu, neighbouring states and few foreign visitors. About 76 questionnaires were administered for analysis. SWOT analysis was made to know the status of tourism in Ooty. The questionnaire contains 38 simple questions and it was given to the visitors to get their opinion.

Opinion was asked to the respondents that whether the tourism activities in Ooty can be conducted purely by ecotourism. About $95 \%$ of the people agreed that it can be converted with ecotourism which can help the local communities. Almost all the people expressed their satisfaction that the tourism and ecotourism activities being conducted in Ooty and surroundings are appreciable. They also opined that the place is very cool, clean and beautiful. Almost all of them generally opined that to keep the Ooty and its natural beauty as such for future generation. Ooty has already faced a huge setback from the point view of carrying capacity at the Botanical Garden, Rose Garden and Boat House. It is suggested that long term monitoring on nature based tourism or ecotourism in and around Ooty should be carried out to evaluate the merits and demerits. 
Keywords: Tourism; Ecotourism; Udhagamandalam; Ooty; Nilgiris; Questionnaire survey 1

\section{Introduction}

Tourism is an important contributor to enrich the economic background of many countries. It is often described as an "Integrated" industry, by having link with many allied sector to provide adequate service to the tourist [1]. There has been considerable academic and policy debate about more integrated and territorial approaches to develop the tourism industry in India. Tourism is a composition of activities, services and industries that deliver a travel experience, transportation, accommodation, eating and drinking, establishments, shops, entertainment, activity facilities and other hospitality services available for individuals or groups travelling away from home. Tourism also encompasses travel for pleasure during holiday, health, business and trade, pilgrimage and social purpose, historical and geographical research, educational purpose, foreign offices and other official functions. Tourism industry has the capacity to transform certain apparent goods/ services that are economically useless into marketable attraction [2].

Eco and Rural tourism are the two thrust area identified by the Ministry of Tourism (MoT) to develop the country's rural part by providing ample business opportunity to enhance the local community people to participate into the tourism activities for their livelihood. But most of the eco and rural tourism destinations in lesser known places are not penetrate themselves into the domain of tourism activities because of non-accessibility, lack of tourist facilities, amenities and tourism infrastructural facilities. The wealth and development measures were concentrated only on the developed tourism destination, where, the lesser known destination are not captured much attention of the state tourism sector, and it denies the economic opportunity of the local people; even the destination has got the potential to become top most tourist hot spot in the country's tourism map. The wide disparities in the development of tourism destinations lead to an inequitable development and it creates unbalanced economic growth. By acknowledging all the mentioned factors, the main aim of the study is to analyse whether to improve the destinations by imposing the new strategic partnership among various stakeholders to ensure the equitable tourism development in the potential area for the development of local community people who rely on tourism sector for their livelihood [3].
Tourism is widely considered to be one of the fastest growing industries in the world, and ecotourism is believed to be its fastest growing subsector, though the definition of the term ecotourism has not been clear to date [4]. Ecotourism is becoming more attractive because it is believed that it makes it possible to improve income generation without harming the environment. Tourism growth provides significant economic benefits such as creating employment and additional income in both host countries and tourists' home countries [5]. According to (Constanta, 2009) [6] tourism can increase quality of life, which is carried out in various forms: rest, relaxation, recreation, maintenance of tone, knowledge development and sense of taste for beauty, aesthetic feelings, cultivate, etc. New jobs emerge, old towns, facilities and places are revitalized and social life significantly improves. Local residents see new business opportunities in tourism and are motivated to explore them. On the social level, it is reported that after tourism enters a community, there is often increased unification of the local residents as they work together toward a common cause [7].

India is a popular tourist destination and in particular it is famous for, an eco and rural tourism destination; Andhra Pradesh, Rajasthan, Tamilnadu, Kerala, Karnataka and Uttar Pradesh are some of the states in India extremely doing well in the promotion of rural and ecotourism and it attracts nearly $85 \%$ of domestic tourists" by providing ample opportunity to the local community people. As a whole, the sector has played a very vital role in strengthening basic infrastructure and as a result it contributed enormous opportunity for social development of the society. Nevertheless, the development activity in the rural and economically weaker part of the country has not been captured under the realm of tourism.

Ooty is one of the mass tourism destination located in the district called Nilgiris, A Blue Mountains of the Western Ghats; it draws a large number of tourists every year. Lofty mountains, great lakes, dense forests, sprawling grasslands, miles of tea gardens and eucalyptus trees greet the visitors while traveling to Ooty. The hill station itself is a land of picturesque picnic spots. It used to be popular summer and weekend getaway for the British peoples during the colonial days, later it was made into a summer administrative town and now it is become one of the major summer spot in south India (WikipediaOoty). The inflow of tourist to Ooty increasing each and 


\section{Journal of Ecology \& Natural Resources}

every year with great extends (Tourist inflow statistics 2008, Govt. of Tamilnadu).

\section{Review of literature}

The review gives a clear perspective of the overall field of research and allows comparing the result of the studies in the particular field with the present research. It provides the researcher with an opportunity of gaining insight into the method and approaches employed by others and help to pursue the research. Sankaran (2009) [8] in his article " A Study on Consumer Perception on Tourist Point in Southern Most Corner of India" attempted to understand the perception of tourist in South corner of India (Kanyakumari). According to this study, the flow of both foreign and domestic tourists has increased during the recent past. Most of the tourists opined that the means of transport was good, at the same time, the behaviours of Transport Authority was not good. Cost of accommodation was moderate and availability and taste of food were satisfactory. Market facility was good but the performance of shopkeepers was not good.

Karanti and Mishra [9] in his book "Promoting Tourism in India - A Case Study", stated that the potential for development of tourism at a given destination depends as much on the availability of a strong tourism resource base, as on the tourist plant facilities in terms of accessibility, internal transportation, accommodation, recreation and entertainment provisions, travel agency and tour operation services, shopping opportunities and so on.

Uma Krishna [10] in her article " Travel and Tourism A Service Marketing Perspective" identified that people in the travel and tourism industry-travel agents, tourist guides, hotel and restaurant staff, transport personnel, etc., played a very important role in brand building and delivering customer satisfaction.

Saravana and Joseph [11] in their study "Cultural Tourism in Kerala: A Study with Special Reference to Malabar" attempted to study the role of Government in promoting cultural tourism in Kerala. They inferred that the main purpose of visit of the domestic and foreign tourists to Malabar has been identified as pleasure. Age has an influence on the travel need by the tourists. Foreigners stay longer days than domestic travelers with their family as they were on a pleasure trip. But they were not satisfied with basic infrastructure facilities. Elangovan and Govindan [12] studied about the perception of tourists in Udhagamandalam area.
International and Domestic tourism is very important for countries with varied attitude and preferences. In the domestic market, the main target audiences are the local residents and the main destinations are places of pilgrimage, beaches, hill stations and resorts. Among the various tourist places, tourists are attracted towards hill stations irrespective of their age, gender, etc. Hence, the study is under taken.

\section{Objectives of the Study}

- To bring out the interest and preferences of tourists visiting Ooty.

- To examine the satisfaction of tourists with respect to visiting Ooty.

- To investigate the problems encountered by the tourists while visiting the hill station.

- To identify the factors influencing the tourists to visit again to this hill stations.

\section{Study area}

"Nilgiris" is the name in Sanskrit means BLUE MOUNTAINS and in Tamil it means NEELAMALAI. The Nilgiris District is situated in the Western Ghats and is surrounded by Coimbatore District, Kerala State and Karnataka State on the Eastern, Western and the Northern side respectively. The Nilgiris District is a celebrated summer resort for the tourist from all over India. Ootacamund or Udhagamandalam rightly described as "Queen of Hill Stations" is spread over an area of 36 Sq.Km. It is the most popular of all the destinations of the Nilgiris. The special attraction of Ooty is its lushy vegetation, the blue screen of the mountain, blue coloured flowers and the mild climate. There are many places of tourist attraction in and around Ooty. Main attraction are the Botanical Garden, Rose Garden, the Dhoddabetta Peak, the Udhagai Lake etc. The development of the Town started from the year 1821 and the town expands its limit year after year. Now it has 32 municipal wards and the expected population by the year 2011 is $1,50,000$. The Udhagai lake was once a part of a west flowing stream. In 1824, the lower part of the stream was converted into a lake. There is a boat house where row boats and motor boats can be had on hired. The original area of the lake was 65 hectares in the year 1823 and it is shrunken to the present status of 23 hectares. The main reasons for the shrinkage of the lake is the encroachment and silt deposition (Map I).

Ooty's economy depends on the factors. The first one is the plantation and the next one is through tourism 
activities. The study was conducted where the places of interest of tourists inside the Ooty municipal limit are:

1. Botanical Garden

\section{Boat House \\ 3. Rose Garden}

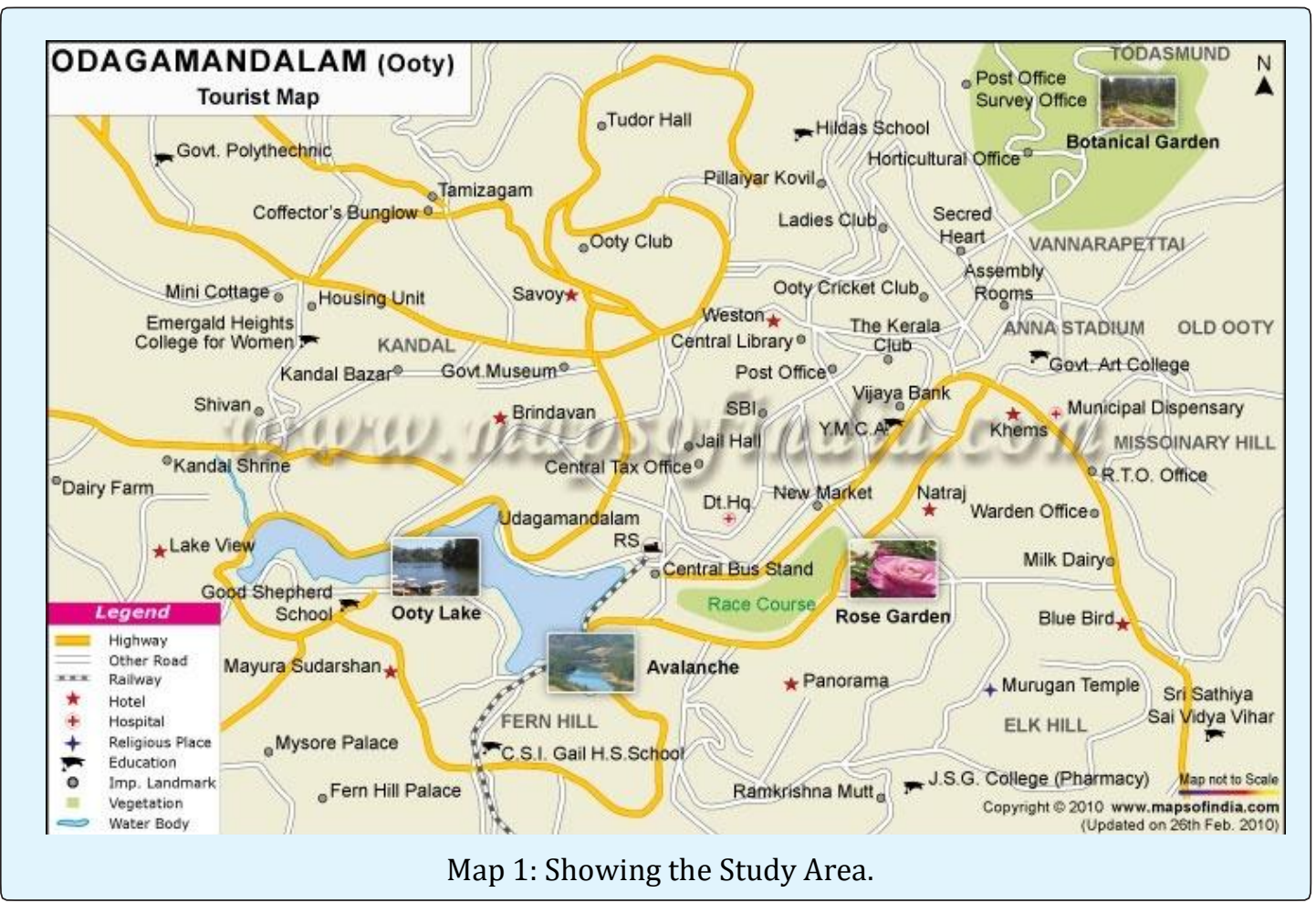

\section{Methodology}

\section{Research Design}

The study is basically exploratory in nature. The study attempts to analyze the tourist's responses regarding various factors of tourism in Ooty. It was done with the help of a questionnaire analysis.

\section{Data Collection Methods}

The collection of data in this study has been through the questionnaire survey method. The present study has been done based on primary data and secondary data. The primary data was collected by administering questionnaires to tourists who have been visiting to Ooty. Secondary data was used, to support the primary data. The major sources of information were the various journals, newspaper reports, research articles, market research agencies and the World Wide Web sites.

\section{Questionnaire Design}

The primary objective of the questionnaire survey was to obtain an insight into the tourists perceptions about
Nilgiris. The questions asked pertained to various factors that affect their stay in Ooty. The resultant final questionnaire was of an intermediate structured accepted type. It contained 38 questions of which some were closed and some were open ended questions.

\section{Sampling Procedure}

The sampling procedure followed was a case of convenient sampling. The target respondents were tourists who had been visiting to Ooty. Questionnaire was surveyed with the tourists of Tamil Nadu, neighbouring states and few foreign visitors. About 76 questionnaires were administered for analysis.

\section{Data Treatment Methods}

The raw data collected from the questionnaires was suitably coded and tabulated to make statistical inference. The data was fed into the Microsoft Excel and analysed using the statistical package called "PAST" (PAleontological STatistics). From this structured data, suitable information was extracted, analyzed, tabulated and illustrated. 


\section{Journal of Ecology \& Natural Resources}

\section{Results and Discussion}

An attempt was made to prepare a SWOT analysis of the tourism activities in and around Ooty for its strength, weakness, opportunity and threats.

\section{'SWOT' Analysis}

\section{Strengths:}

- Pleasant weather which is ideal for the tourists to come for the annual summer holiday to escape the scorching heat of the plains.

- Scenic beauty of the Nilgiris, which draws tourists away from the crowded and polluted towns and cities.

- Terrain is ideally suited for various adventure activities.

- Ooty is very well known tourist hill- stations.

- It can attract tourists throughout the year.

- Hospitable people

- Indigenous people of their own land

\section{Weaknesses}

- Inadequacy of transport facilities such as air and rail

- Funds constraining the development of regions.

- Inadequacy of information channels.

- Overcrowding of popular tourist centres.

- Some places are inaccessible, especially in winter.

- Lack of adequate infrastructural support.

\section{Opportunities}

- The concept of holidaying is gaining popularity in India among various classes of people.
- Increased disposable incomes of the Indian middle class.

- Adventure sports and trekking.

- Eco- tourism is gaining popularity.

- Nilgiris contains many unexplored regions.

\section{Threats}

- Nilgiri is being opened up and could divert a large portion of tourists.

- Various other places in India are providing stiff competition.

- Environmental factors also impose a threat.

- Development and mushrooming of buildings

- Changing style of indigenous people and their culture

\section{Questionnaire Survey}

Questionnaire survey was made to the visitors who visit different parts of the country and abroad. The questionnaire contains 38 simple questions and it was given to the visitors to get their opinion. Most of the visitors hesitate to fill the questions and opined that it is too length. Few of them actively filled the questionnaire.

The opinion survey was made to different people who visits from Tamil Nadu, Kerala, Karnataka and for away from Ooty. Few samples were also taken from the tourists who visits from abroad. Most of the survey was conducted to the visitors from Tamil Nadu and nearby states, because they were the majority during the survey (Figure 1). Of the total of 76 questions made $62 \%$ were males and $38 \%$ are females.

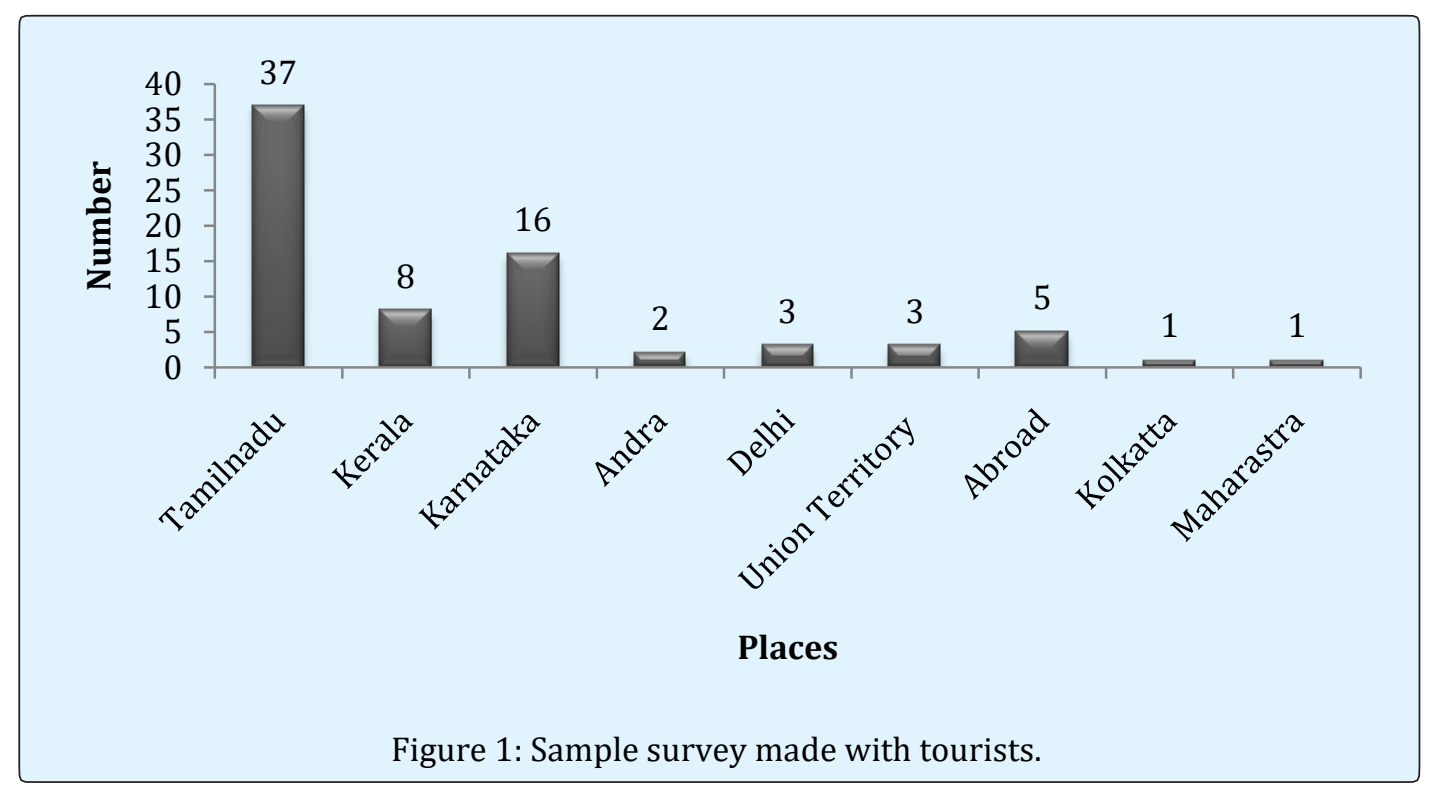

Veeramani A, et al. Tourism 'Vs.' Ecotourism - People Perception in Upper Nilgiris, Tamil Nadu, India. J Ecol \& Nat Resour 2018, 2(6): 000148. 


\section{Journal of Ecology \& Natural Resources}

\section{Age group}

Most of the questionnaires were made to the visitors at the age group of below 30 years old. Because they were having more awareness about the impact of tourism and they are more educated. They were also very much interested to fill the questions. Among the visitors about $86 \%$ of them were visited Ooty more than one time. The majority of visits to Ooty shows the interest of tourists and attraction of the place.

\section{General Information's}

Of the visitors, about $39 \%$ of them opined that they got information about the place from website. Twenty eight percent of them opined they got information from the person who visits Ooty in the past. Most of the people opined that they spent holidays in the hill stations and they are visiting this place with their own interest (55\%). Very few of them says (5\%) they visits to see wild animals. People also visits Ooty to enjoy the culture and climate. Enquiries were also made to the visitors about the most competitors for this place in tourism development in the country. Most of them are opined that Munnar and Kodaikanal are the most competing places, followed by Kerala particularly Kochi and Alapuzha and Goa. About 20\% of the people opined that they do not have any idea about this (Figure 2).

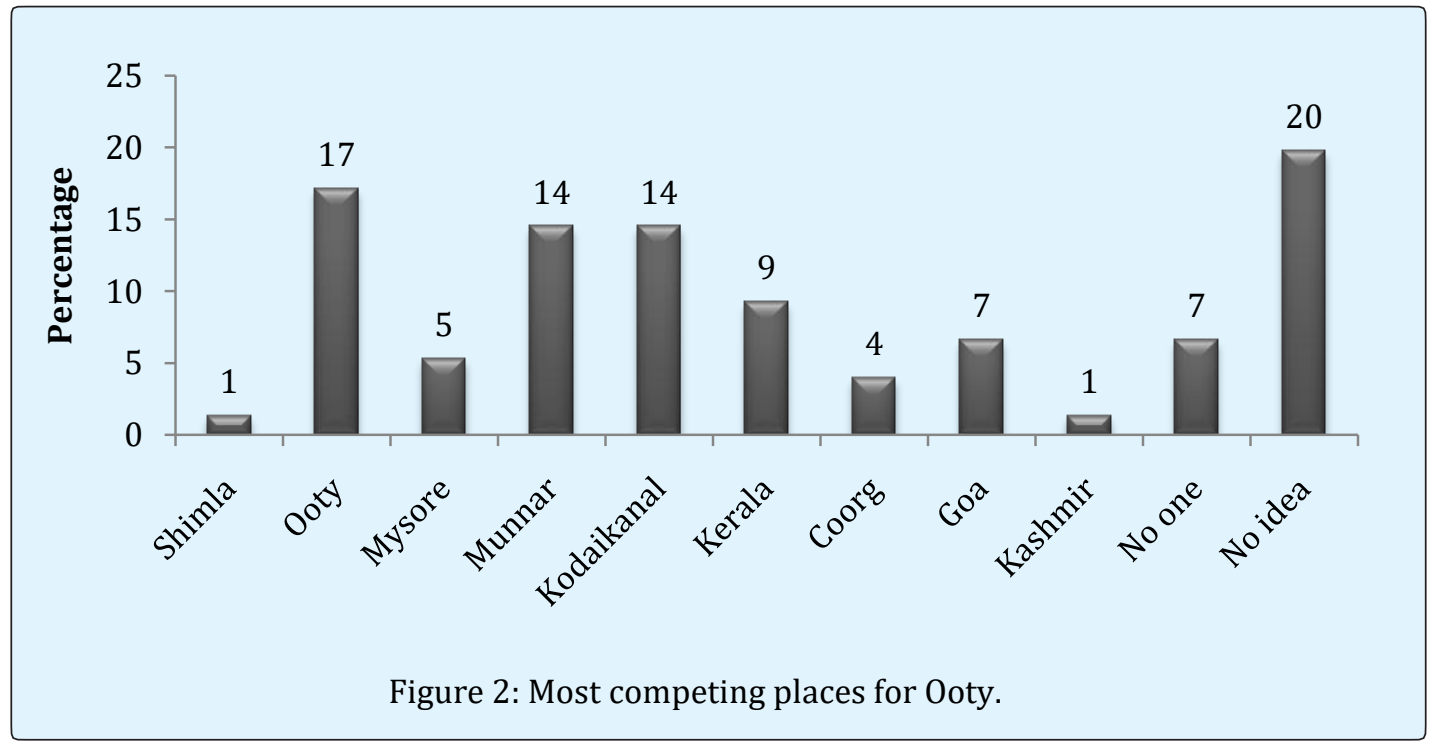

\section{Information about Tourism}

Enquiries were also made about the informations provided in the official website are attractive and informative. Sixty six percentage of the people opined that it is informative. The visitors were asked about the attractive tourism programmes being conducted in Ooty. Almost all the respondents opined that they liked all the programmes in particular Botanical garden, Doddapetta, Rose Garden, Ooty Lake Boat house, Pykara boating, Mudumalai, etc. The information provided by the tourism information centre was appreciated by many tourists. About $47 \%$ of the tourists opined that it is upto the level of average followed by $30 \%$ are said it is useful. Twenty three percent of the people opined that there is no use of information centre which is not providing proper information.
About $89 \%$ of the respondents opined that the infrastructure facilities are not sufficient and it should be improved for the visitors and only $11 \%$ of them replied it is sufficient. Similarly the visitors were asked about the cleanliness of the area. Eighty three percent of them opined that the tourism areas are clean and neat and only $17 \%$ said it is not clean. Opinion was asked to the tourist whether they know about Ooty is a plastic free zone. About $74 \%$ of them opined that they know about it and rest of the $26 \%$ are do not know, the Ooty Municipality declared the area is plastic free zone.

The tourists were asked about the indigenous community living in Nilgiris. About $74 \%$ of them opined that they know about the Thoda and Kurumba tribals. And $26 \%$ of them said they do not know about the indigenous community living in Ooty. Awareness about 


\section{Journal of Ecology \& Natural Resources}

the cultural values of the Nilgiris was asked to the tourist. Only $17 \%$ of them were responded that they know it. Majority of $83 \%$ opined that they do not know the cultural values of Nilgiris.

\section{Knowledge about Wildlife}

Knowledge about the wildlife in and around Ooty was enquired to the tourist. Only $13 \%$ of them were responded it is good and most of them $87 \%$ opined that they do not have any idea about the wildlife. The tourist were also enquired about whether they have come across any wild animals. About $36 \%$ of them said they had seen elephant, monkeys and deers. Only one person said he had seen a tiger at Mudumalai Tiger Reserve. About 64\% of the respondents revealed that they did not see any wild animals.

Visitors were also enquired about the endemism or endemic mammals, birds, reptiles, amphibians and butterflies in Nilgiris. Majority of them opined that they do not know the endemism of wildlife. Only two of the respondents opined that they had seen Nilgiri tahr and one person said he seen a Nilgiri laughing thrush. Questions were also asked to the tourist about how the tourism is helpful for conservation of wildlife in the area. Only $4 \%$ of them had the awareness that the ecotourism helps the local community and help in forest protection through which the wildlife also getting benefitted. Majority of $96 \%$ says they do not know about the tourism helps for wildlife conservation.

Enquiries about the wildlife wealth and passing of information to the public were asked to the visitors. Only $13 \%$ of them say they get enough information about the wealth of wildlife. Similarly $29 \%$ of the tourist opined that the tour operators have major role about passing information about wildlife to the tourists. Fifty three percent of the people said they do not know who has to involve in passing information about wildlife to the tourists. Very few of the people opined that the Government and NGO's have severe role in this matter.

\section{Ecotourism}

Opinion was asked to the respondents that whether the tourism activities in Ooty can be conducted purely by ecotourism. About $95 \%$ of the people agreed that it can be converted with ecotourism which can help the local communities. They were also asked for their opinion about ecotourism activities conducted in and around Ooty. Sixty two percent of the people opined that it is average and $28 \%$ said it is excellent. Five percent each of the people said it is good and bad (Figure 3).

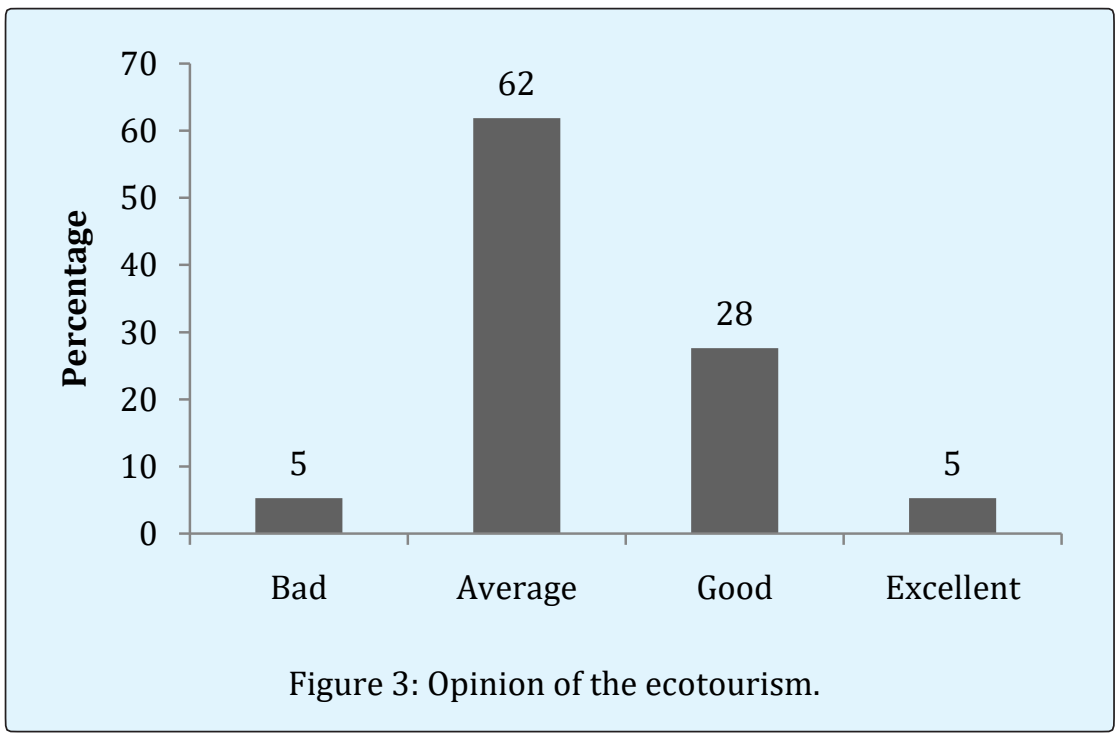

The visitors were also asked about whether they will share their experience in participating ecotourism programmes to their friends. Majority of the people $96 \%$ opined that definitely they will share their experience to other. The visitors were also asked whether they will persuade their friends to visit Ooty and participate the ecotourism programmes. Ninety three percent of the visitors told they will do it. Likewise, $82 \%$ of the people said they do not know the eco-friendly products sold in Nilgiris. 


\section{Journal of Ecology \& Natural Resources}

\section{Accommodation}

The visitors were also asked about their stay in Ooty. Thirty three percent of the visitors said they are staying in Cottages and 25\% were staying in Guest house. Thirteen percent of the visitors are the day visitors (Figure 4). Most of the tourists prefer to stay one day only (32\%), where as $25 \%$ of them stay for about two days. Only $4 \%$ percent of the tourists stay for about a week.

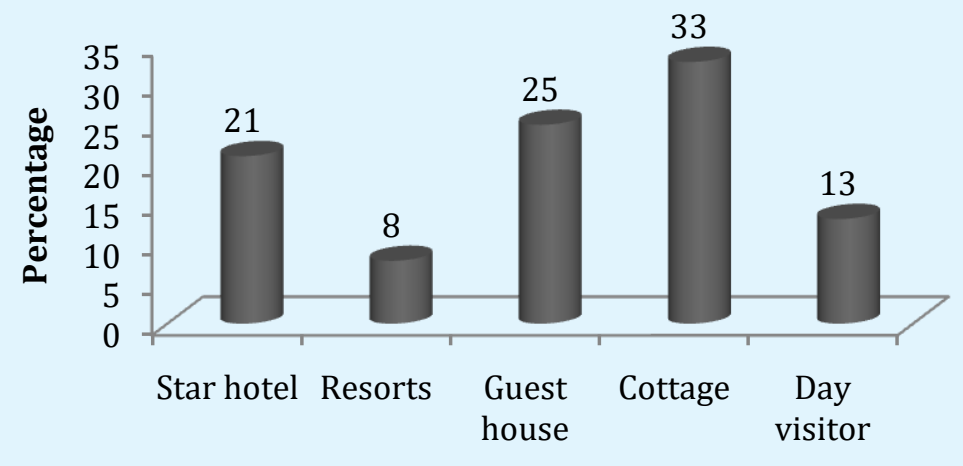

Figure 4: Enquiries about Accommodation.

\section{General Opinion}

The tourists were also enquired about the ecotourism products are affordable to all the tourists. Majority of people (71\%) says it is affordable to all. And the visitors also asked about whether they will come back again to Ooty and participate ecotourism activities. About $95 \%$ of them happily told they will come again with family. About $75 \%$ of the tourists expressed their opinion on the rules and regulation followed by the government is satisfactory.

Almost all the people expressed their satisfaction that the tourism and ecotourism activities being conducted in Ooty and surroundings are appreciable. They also opined that the place is very cool, clean and beautiful. Almost all of them generally opined that to keep the Ooty and its natural beauty as such for future generation.

\section{Conclusion and findings}

In the era of the globalization, privatization and modernization, Travel and Tourism has been growing rapidly across the globe. In one way, it gives several positive impacts on tourism development, such as foreign exchange earnings, employment opportunities, economic multiplier effects, destination development etc. On the other hand, there are several negative impacts at the destinations, such as overcrowding and congestion, pollution, deforestation and parking problem, visual pollution etc.
Community participation is an important dimension of the study with in-depth analysis on the socio-economic background and the valued opinions of the community respondents on the practices of nature-based tourism in Ooty. The inclusion of the community in the study has offered two benefits of approaching the study. The first benefit is to find the prevailing socio-economic and cultural conditions of the local population who are directly and indirectly associated with the tourism development. The second benefit is to understand the attitude of the community towards the prevailing tourism practices.

The study has suggested for implementing strategies to realize the prospects of sustainable nature tourism model for ensuring equity in development. The scope of the study is only confined to tourist, community and service providers, because these stockholders are directly interdependent and complementary to each other. The study has revealed some genuine findings which are presented in a logical way. Having been guided by the existing gap in the theory and practices, the study was undertaken with an argument that Ooty's nature-based tourism needs to be sustainable for future by assessing the present state of carrying capacity conditions and community participation. As such, Ooty has already faced a huge setback from the point view of carrying capacity at the Botanical Garden, Rose Garden and Boat House. It is suggested that long term monitoring on nature based 
tourism or ecotourism in and around Ooty should be carried out to evaluate the merits and demerits.

\section{Major Findings}

\section{Unprecedented Tourist Inflows}

Ooty, being a most preferred hill station in South India, the highest foreign and domestic tourist arrivals is reported as compared to other hill stations in Tamil Nadu. It is ascertained from the analysis that Ooty has already faced the heat of the unprecedented tourism inflows and it all appears to be one of the mass tourism destinations in the near future. However, Ooty is no longer regarded as a special interest destination to attract niche tourism, as it is evident from the tourist statistics.

\section{Tourist Arrivals in the Ecotourism Sites in Tamil Nadu}

Out of the six ecotourism sites, such as Ooty, Kodaikanal, Yercaud, Elagiri, Coonoor and Mudumalai, Ooty has maintained the position as the first hill station or nature-based tourism. Ecotourism and nature-based tourism as its two principal forms of attractions in Ooty have been alluring the tourists in large number. Thus, the increase in tourist arrivals to Ooty has thrown many challenges such as carrying capacity, community participation, and socio-cultural impacts. Most of the tourists visits Ooty opined that the tourism should be changed as ecotourism sites to maintain the nature beauty as such.

\section{Mushrooming Unapproved Hotel/ Guest House/ Boarding and Lodging}

The widespread commercialization of Ooty as a hill station without corresponding improvements in hotel infrastructure and amenities has a direct fall out on the carrying capacity. With the mushrooming growth of the hotels, guesthouses and boarding and lodging during late 1980s. Ooty started facing the serious problems of sewerage, deforestation, crowd and congestion, air pollution, aesthetic pollution, host-guest conflicts and erosion of socio-cultural values.

\section{Summary}

Tourism is an important contributor to enrich the economic background of many countries. Tourism is a composition of activities, services and industries that deliver a travel experience, transportation, accommodation, eating and drinking, establishments, shops, entertainment, activity facilities and other hospitality services available for individuals or groups travelling away from home. Tourism is widely considered to be one of the fastest growing industries in the world, and ecotourism is believed to be its fastest growing subsector, though the definition of the term ecotourism has not been clear to date. Ecotourism is becoming more attractive because it is believed that it makes it possible to improve income generation without harming the environment.

\section{References}

1. Bramwell B, Lane B (2000) Tourism collaboration and partnerships, Politics, Practices and sustainability, Aspects of tourism: Channel view Publication, pp: 1-19.

2. Renuga devi V, Thamilselvi T (2013) Prefernces and satisfaction of domestic tourists visiting hill stations in Tamil Nadu. Primax Int J Com Manage Res 1(2): 7080.

3. Saravanan A, Rao YV (2012) Equitable tourism development: Need for strategic partnership. Int J Multi discipilinary Res 2(3): 344-356.

4. Buckley R (1994) A Framework for Ecotourism. Annals of Tourism Research 21(3): 661-665.

5. Delibasic R (2008) Quality of life and tourism in Budecsko. J Sustainable Tourism 1(2): 112-120.

6. Constanta E (2009) The impact of tourism in enhancing the quality of life. Review Int Comparative Management 10(2): 347-351.

7. Fennell DA (2003) Ecotourism: An introduction. London: Routledge.

8. Sankaran A (2009) A Study on Consumer Perception on Tourist Point in Southern Most Corner of India. South Asian J Social-Political Stud 9(2): 162-165.

9. Karanti P, Sowarkar, Subodh KM (2010) Promoting Tourism in India - A Case Study. New Delhi: Kanishka Publishers and Distributors.

10. Uma K (2010) Travel and Tourism - A Service Marketing Perspective. Marketing Mastermind X(6).

11. Saravana K, Joseph MA (2011) Cultural Tourism in Kerala: A Study with Special Reference to Malabar. Southern Economist 50(11): 11-14.

12. Elangovan A, Govindan P (2013) A study on tourist's satisfaction with special reference with to Udhagamandalam. Int J Sci Res 2(2): 46-47. 